\title{
Enhanced Antibacterial Efficiency of Cellulosic Fibers: Microencapsulation and Green Grafting Strategies
}

\author{
Dorra Dridi $^{1,+}$, Aicha Bouaziz ${ }^{2,3, \dagger}$, Sondes Gargoubi ${ }^{4, *}$, Abir Zouari ${ }^{5}$, Fatma B'chir ${ }^{6}$, Aghleb Bartegi ${ }^{2}$, \\ Hatem Majdoub ${ }^{7}$ (D) and Chedly Boudokhane ${ }^{5}$
}

1 Unit of Analysis and Process Applied to the Environment (UR17ES32) Issat Mahdia, Department of Environmental Sciences \& Nutrition, University of Monastir, Monastir 5000, Tunisia; dorra.dridi.jeddi@gmail.com

2 Bio-Resources, Integrative Biology \& Valorization (BIOLIVAL, LR14ES06), Higher Institute of Biotechnology of Monastir, University of Monastir, Monastir 5000, Tunisia; bouaziz.aicha@gmail.com (A.B.); a.bartegi@gmail.com (A.B.)

3 Higher School of Health Sciences and Techniques of Sousse, University of Sousse, Sousse 4054, Tunisia

4 Textile Engineering Laboratory-LGTex, Textile Department, University of Monastir, Monastir 5000, Tunisia

5 Research Unity of Applied Chemistry and Environment, Faculty of Science of Monastir, University of Monastir, Monastir 5000, Tunisia; zouariabir2@gmail.com (A.Z.); chimi.tex@planet.tn (C.B.)

6 Research Department, Institute National de Recherche et d'Analyse Physico-Chimique-Pôle Technologique de Sidi Thabet, Sidi Thabet 2020, Tunisia; bchirbnfatma@gmail.com

7 Laboratory of Advanced Materials and Interfaces, Faculty of Sciences of Monastir, University of Monastir, Monastir 5000, Tunisia; hatemmajdoub.fsm@gmail.com

* Correspondence: gargoubisondes@yahoo.fr

$\dagger \quad$ D. Dridi and A. Bouaziz contributed equally to this work as first authors.

check for updates

Citation: Dridi, D.; Bouaziz, A.; Gargoubi, S.; Zouari, A.; B'chir, F.; Bartegi, A.; Majdoub, H.; Boudokhane, C. Enhanced Antibacterial Efficiency of Cellulosic Fibers: Microencapsulation and Green Grafting Strategies. Coatings 2021, 11, 980. https://doi.org/ 10.3390/coatings11080980

Received: 8 July 2021

Accepted: 12 August 2021

Published: 18 August 2021

Publisher's Note: MDPI stays neutral with regard to jurisdictional claims in published maps and institutional affiliations.

Copyright: (c) 2021 by the authors. Licensee MDPI, Basel, Switzerland. This article is an open access article distributed under the terms and conditions of the Creative Commons Attribution (CC BY) license (https:/ / creativecommons.org/licenses/by/ $4.0 /)$.

\begin{abstract}
We report an analysis of chemical components of essential oils from barks of Ceylon cinnamon and cloves of Syzygium aromaticum and an investigation of their antibacterial activity. The components of oils were determined by using Gas Chromatography/Mass Spectrometry (GC-MS) analysis, and the antimicrobial activity was assessed by the disk diffusion test. The synergic effect of essential oils mixture (cinnamon oil and clove oil) was evaluated. Antimicrobial properties were conferred to cellulosic fibers through microencapsulation using citric acid as a green binding agent. Essential oil mixture was encapsulated by coacervation using chitosan as a wall material and sodium hydroxide as a hardening agent. The diameter of the produced microcapsules varies between 12 and $48 \mu \mathrm{m}$. Attachment of the produced microcapsules onto cotton fabrics surface was confirmed by Attenuated Total Reflectance-Fourier Transformed Infrared (ATR-FTIR) spectroscopy, optical microscopy and Scanning Electron Microscopy (SEM) analysis. The results show that microcapsules were successfully attached on cotton fabric surfaces, imparting antibacterial activity without significantly affecting their properties. The finished cotton fabrics exhibited good mechanical properties and wettability.
\end{abstract}

Keywords: cotton; microcapsules; chitosan; essential oil; antibacterial activity

\section{Introduction}

One year ago, the coronavirus disease of 2019 (COVID-19) crisis forced us into confinement. The unexpected pandemic highlighted how infectious diseases can affect health and economies worldwide. As most countries slowly move toward recovery, considerable attention must be paid to the emergence of multi-resistant microorganisms. The fact that some infectious diseases can no longer be treated with antibiotics depicts an alarming issue in the health care sector [1]. This trend reinforces the need for improved measures to protect and save lives. The resistance to antimicrobial agents is due to the intensive and inappropriate use of antibiotics, self-drug addiction, hospital-acquired infections, unsafe disposal of hospital and biomedical wastes and the use of antibiotics in veterinary medicine [2]. 
The demand for antimicrobial agents with high disinfection properties is on the rise. Effective and safe microbe-resistant materials are highly demanded to fight against the emergence of microbial contamination $[3,4]$.

Plant-based antimicrobial substances are emerging as promising tools in the fight against multi-resistant pathogens, as reported by numerous recent studies [5]. Plants contain valuable components, such as glycosides, tannins, steroids, terpenoids, saponins, alkaloids, polyphenols, flavonoids, quinones and coumarins [6]. These substances are used as a defensive response to microorganisms, insects and herbivores [7].

Among the plant-derived products, essential oils are one of the most diverse classes of specialized metabolites that play an important role in the defense against microbial attacks [8]. Essential oils present a complex mixture of numerous volatile molecules with low molecular weight, including terpenoides, terpenes and other aliphatic and aromatic substances [9]. These constituents exhibit a broad spectrum of antimicrobial activities [10]. In addition, essential oils are biodegradable and safe for human health [11].

Increasing demand for effective and low-toxicity antimicrobial agents depicts essential oils as promising alternatives in a variety of domains [12]. Given the emergence of techniques such as microencapsulation and nanotechnology applications $[13,14]$, the use of essential oils in the textile sector is emerging. These substances are used to impart either a pleasant smell or antimicrobial activity to the textile materials [13].

Microencapsulation and nano-finishing provide good efficacy for treated textiles. In comparison to conventional techniques, the large surface area of micro/nano particles ensures better affinity for textile substrates and leads to a successful and durable functionalization [15].

Despite numerous studies showing the antimicrobial action of essential oils when applied to textiles, the synergistic effect of these substances for textile applications has not been reported [16].

In the current work, we report an environmentally friendly finishing method to functionalize cotton fabric surfaces with antibacterial activity based on the synergic effect of two essential oils attached via a microencapsulation technique with citric acid as a binding agent using the padding method.

\section{Materials and Methods}

\subsection{Materials}

Essential oils were obtained from the bark of Ceylon cinnamon and cloves of Syzygium aromaticum, which were purchased from spice shops. Cinnamon and clove are commonly used spices which have been well recognized for their antimicrobial activities [17,18].

Chitosan (low molecular weight), acetic acid and $\mathrm{NaOH}$ were purchased from Sigma Aldrich (Sigma-Aldrich Chemie GmbH, Steinheim, Germany). Citric acid and Tween 20 (surfactant) were donated by the S2C Company (S2C, Sousse, Tunisia). The desized, bleached and mercerized woven cotton fabric used during the experiments was bought from the local market with a surface area of $280 \mathrm{~g} \cdot \mathrm{m}^{-2}$.

\subsection{Methods}

\subsubsection{Essential Oil Extraction}

Hydro-distillation was used to extract essential oils. The plant material (mashed cinnamon barks/cloves) was laid out with water, boiled and then concentrated by an evaporator with heat at low pressure. The essential oil was transferred through the steam toward a condenser where the oil was separated from the cooled steam using a separatory funnel and collected in a receiving container.

\subsubsection{Microcapsule Preparation}

Chitosan-essential oil microcapsules were prepared by coacervation technique as described in the literature with some modifications [19]. Chitosan solution was prepared by dissolving $1 \mathrm{~g}$ of chitosan in $100 \mathrm{~mL}$ of $1 \%(v / v)$ aqueous acetic acid solution. The 
resulting system was left under magnetic agitation for $3 \mathrm{~h}$. Chitosan was used to form the wall membrane of microcapsules.

An amount of $20 \mathrm{~mL}$ of a mixture of cinnamon and clove essential oil $(1: 1 \mathrm{v} / \mathrm{v})$ was added to the prepared chitosan solution. Then, $0.1 \mathrm{~mL}$ of surfactant (Tween 20) was added to the system.

To form an oil-water emulsion, the system was emulsified at a speed rate of $900 \mathrm{rpm}$ using an Ultra-Turrax (IKA, Staufen, Germany). Coacervation was induced by adding the obtained emulsion to a solution $(250 \mathrm{~mL})$ containing sodium hydroxide $(0.2 \mathrm{M})$ and ethanol (4/1). The stirring speed was reduced to $400 \mathrm{rpm}$. The microcapsules were washed with ultrapure water and collected by decantation.

\subsubsection{Green Grafting of the Microcapsules}

A green binding agent (citric acid) was used to attach the shell material based on chitosan to the cellulosic fibers through ester bonds. The padding drying method was applied as reported in previous studies, with a few rectifications.

The cotton samples were immersed in an aqueous solution $(\mathrm{pH}=5)$ containing $100 \mathrm{~g} \cdot \mathrm{L}^{-1}$ of the microcapsule emulsion, $30 \mathrm{~g} \cdot \mathrm{L}^{-1}$ of citric acid and $2 \mathrm{~g} \cdot \mathrm{L}^{-1}$ of monosodium phosphate (a catalyst). The system was heated at $50{ }^{\circ} \mathrm{C}$ for $5 \mathrm{~min}$. Finally, samples were washed with ultrapure water and padded to obtain a wet pickup percentage of $80 \%$. Drying was carried out at $90{ }^{\circ} \mathrm{C}$ for $5 \mathrm{~min}$ and thermocondensation at $120{ }^{\circ} \mathrm{C}$ for $5 \mathrm{~min}$.

\subsection{FTIR Analysis}

In order to evidence the crosslinking of microcapsules on cotton fabrics, Attenuated Total Reflectance-Fourier Transformed Infrared (ATR-FTIR) spectra were recorded using a spectrophotometer (ATR-FTIR, Perkin Elmer, Waltham, MA, USA). The spectra were collected in transmittance mode with a spectral resolution of 32 scans and $4 \mathrm{~cm}^{-1}$ over the range of $4000-400 \mathrm{~cm}^{-1}$.

\subsection{GC-MS Analysis}

Extracted oils were analysed by Gas Chromatography/Mass Spectrometry (GC/MS) provided with HP-5MS fused-5\% phenyl methyl siloxane capillary column $(30 \mathrm{~m}, 0.25 \mathrm{~mm}$, $0.25 \mu \mathrm{m}$ ) (Agilent Technologies, Santa Clara, CA, USA) and interfaced with a PerkinElmer Turbo mass spectrometer (Software version 4.1) (PerkinElmer, Inc., Waltham, MA, USA). The column operation conditions were adjusted in the following manner: the sample solution injected was $1 \mu \mathrm{L}$, the carrier gas (helium) was adjusted at $1.0 \mathrm{~mL} / \mathrm{min}$, the injector was set at 250 , the ion source temperature was regulated at $200{ }^{\circ} \mathrm{C}$, the split ratio was $100: 1$, the electron impact ionization was of $70 \mathrm{eV}$ and the interface line temperature was set at $300{ }^{\circ} \mathrm{C}$. The operating temperature started at $110{ }^{\circ} \mathrm{C}$, then was gradually raised to $180{ }^{\circ} \mathrm{C}$ with a gradient of $4{ }^{\circ} \mathrm{C} / \mathrm{min}$, then $220^{\circ} \mathrm{C}$ with a gradient of $2{ }^{\circ} \mathrm{C} / \mathrm{min}$, and reached $300{ }^{\circ} \mathrm{C}$ at a gradient of $20^{\circ} \mathrm{C} / \mathrm{min}$.

\subsection{Optical Microscopy}

In order to confirm that essential oils were successfully microencapsulated, an optical microscope (Leica DM 500, Leica Microsystems, Heerbrugg, Switzerland) was employed.

The optical microscope is equipped with a digital camera controlled by analysis software and different objectives. Microscopy technique was also considered to control the size and size distribution of microcapsules.

\subsubsection{Scanning Electron Microscopy}

Morphological analysis was performed using a high-resolution scanning electron microscope (FEIQ250, Thermo-Fisher ESEM, Waltham, MA, USA). The cotton samples were coated with a conductive gold layer (a thin layer) by vapor deposition. Imaging parameters were regulated at low working voltages $(5-10 \mathrm{kV})$ to save the original state of the textile material. 


\subsubsection{Mechanical Properties}

Tensile strength tests were conducted using a dynamometer (Lloyd LR $5 \mathrm{~K}$, Lloyd Instruments Ltd., Largo, FL, USA). Samples were cut to a gauge length of $75 \mathrm{~mm}$, and tests were performed as stated by NF EN ISO 13934-2 standards using a load cell of $5 \mathrm{kN}$ and an extension speed of $50 \mathrm{~mm} \cdot \mathrm{min}^{-1}$.

\subsubsection{Surface Wettability}

The contact angle aspects were recorded using a Drop Shape Analyzer (DSA25, Kruss, Germany). A droplet of $2 \mu \mathrm{L}$ of ultra-pure water was placed on the fabric surface immobilized on the stage. For each sample, the test was repeated three times in different places.

\subsubsection{Washing Durability}

To evaluate the washing durability, a domestic washing cycle was conducted as described in our previous publication [20]. A qualitative evaluation of the microcapsules crosslinking was realized based on optical microscope photographs.

\subsection{Antibacterial Activity}

The agar diffusion method was applied to evaluate essential oil activity. The cell density was adjusted to approximately $10^{6} \mathrm{CFU} / \mathrm{mL}$. An amount of $100 \mathrm{~mL}$ of the inoculi was spread over each petri dish containing the nutrient agar (Mueller-Hinton Agar). A paper filter disc $(5 \mathrm{~mm}$ ) impregnated with $20 \mu \mathrm{L} /$ disc of the essential oils (cinnamon oil, cloves oil and oil mixture 50/50) was placed on the surface of the petri dishes, which were then incubated at $37^{\circ} \mathrm{C}$ for $24 \mathrm{~h}$. Each test was repeated twice.

The same method was applied to evaluate the activity of treated textiles against bacteria. All the tests were performed using the strains Staphylococcus aureus (ATCC 25923) and Escherichia coli (ATCC 8739). An autoclave was used, before experiments, for instruments and fabrics sterilization by heated steam at $120^{\circ} \mathrm{C}$ for $20 \mathrm{~min}$.

\section{Results and Discussion}

\subsection{Essential Oil Extraction and Characterization}

The hydro-distillation of the barks of Ceylon cinnamon and cloves of Syzygium aromaticum produced essential oils in yields of $1.8 \%$ and $10.5 \%, v / w$, respectively, based on fresh weight.

The phytochemical composition of the two extracted oils was determined using a gas chromatograph coupled with a mass selective detector.

The composition of clove and cinnamon essential oils were found to be diverse. The major active constituents of clove essential oil were eugenol (83.55\%) and phenol, 2-methoxy-4-(2-propenyl)-, acetate (14.92\%), while the main active constituents of cinnamon essential oil were cinnamaldheyde $(28.37 \%)$ and cinnamyl acetate $(22.63 \%)$.

\subsection{Morphology and Size of Microcapsules}

Figure 1a shows an optical photograph of essential oil-loaded microcapsules. Figure $1 \mathrm{~b}$ shows the optical microscopy of a microcapsule on the cellulosic fiber surface. The prepared microcapsules clearly show regular and spherical structures without fragments.

Figure $1 \mathrm{~b}$ evidences the crosslinking of microcapsules on the fabric surface conserving their spherical shape. Figure 1c shows the cellulosic fiber, after a cycle of domestic washing, on which we can clearly identify an attached microcapsule.

Finally, Figure 1d shows the SEM images, at different magnifications, of a ruptured microcapsule after lightly rubbing the fabric. The crushed microcapsule presents a rough shell wall. 

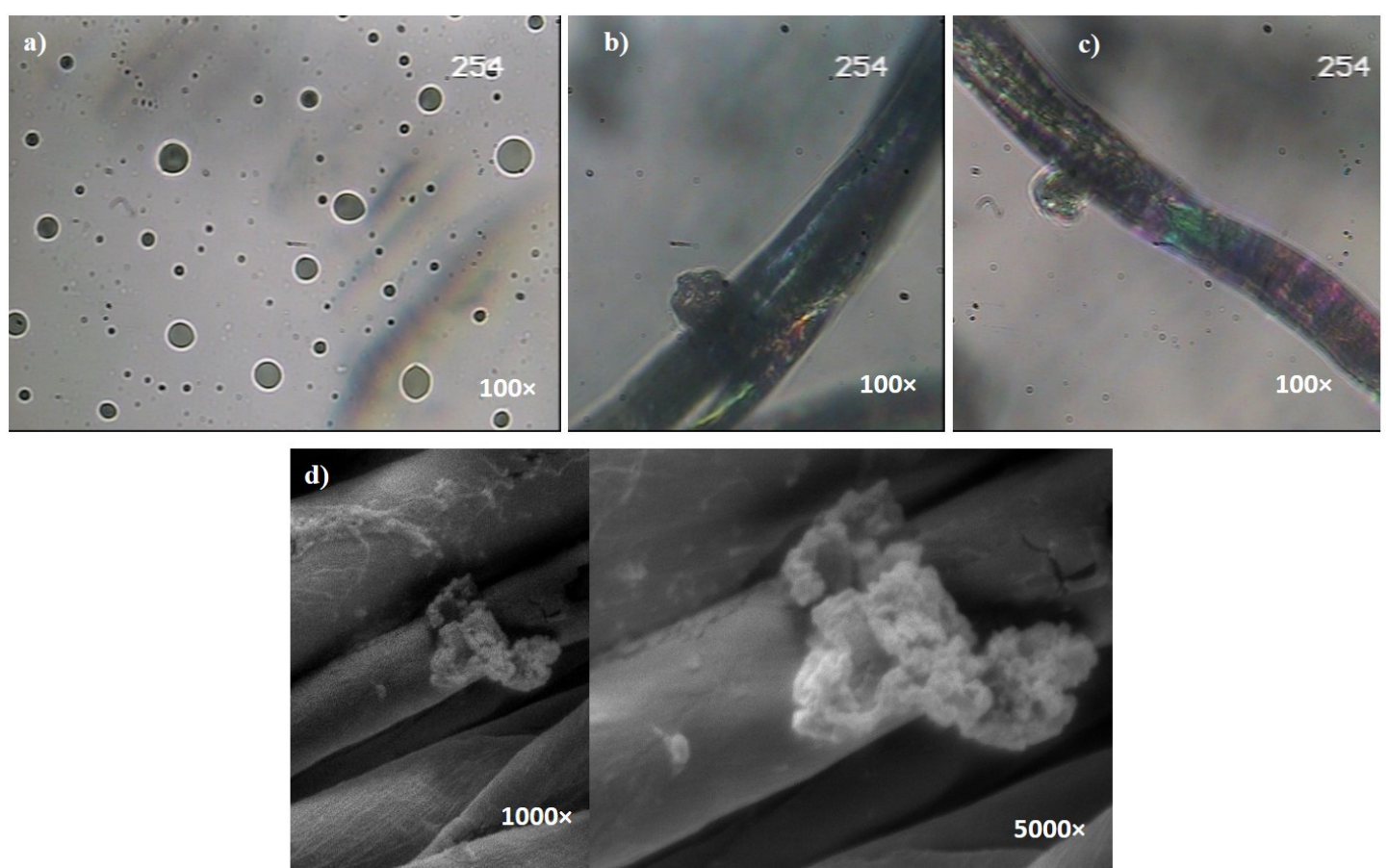

Figure 1. Optical photographs of (a) microcapsule solution, (b) microcapsules on the surface of the cellulosic fiber, (c) microcapsules on the surface of the cellulosic fiber after washing and (d) SEM images of ruptured microcapsule at different magnifications (the inset in $\mathbf{d}$ ) is the ruptured microcapsule at $1000 \times$ magnification).

The microcapsule size distribution was evaluated by optical microscopy. The size of 80 microcapsules was determined. Figure 2 shows the size distribution of prepared microcapsules is between 12 and $48 \mu \mathrm{m}$, and the mean diameter is $22 \mu \mathrm{m}$. It was reported that the non-uniformity of size distribution is due to the stirring process. The wateroil emulsion flows rapidly around the agitator. The microcapsules with larger size are formed far away from the agitator, while small microcapsules are formed near the agitator [21]. In addition, the agglomeration of the oil phase enhances the non-uniformity of the microcapsules' size [22].

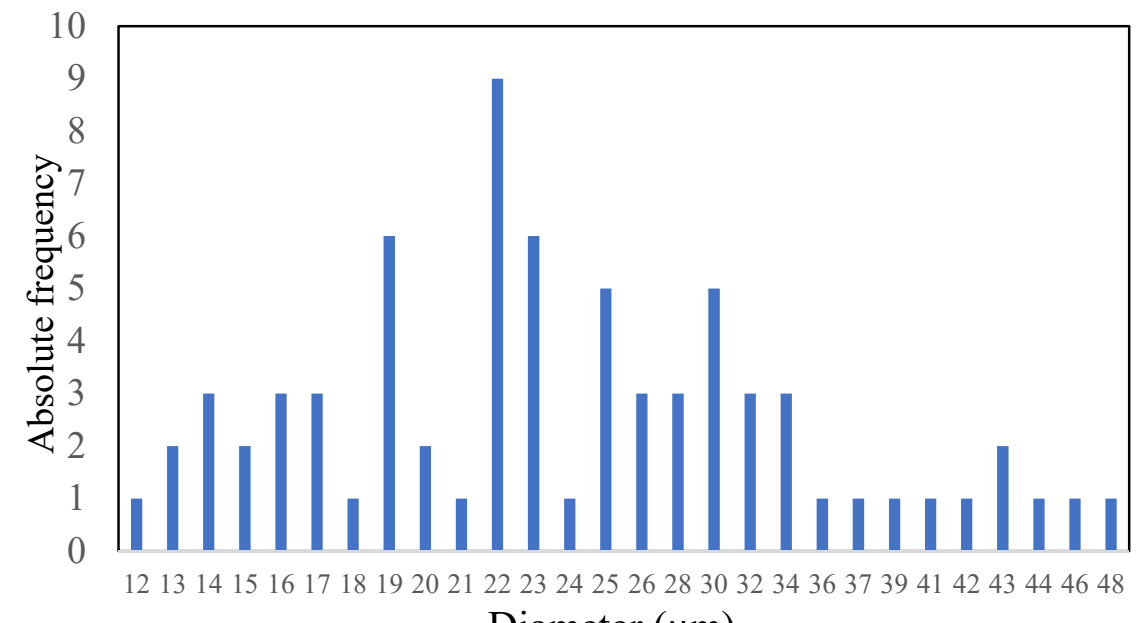

Diameter $(\mu \mathrm{m})$

Figure 2. Microcapsule size distribution. 


\subsection{ATR-FTIR Results}

In order to evaluate the success of the attachment of microcapsules on the surface of the cellulosic fibers through the citric acid, the control fabric (untreated cotton) and the treated fabric were characterized by ATR-FTIR (Figure 3).

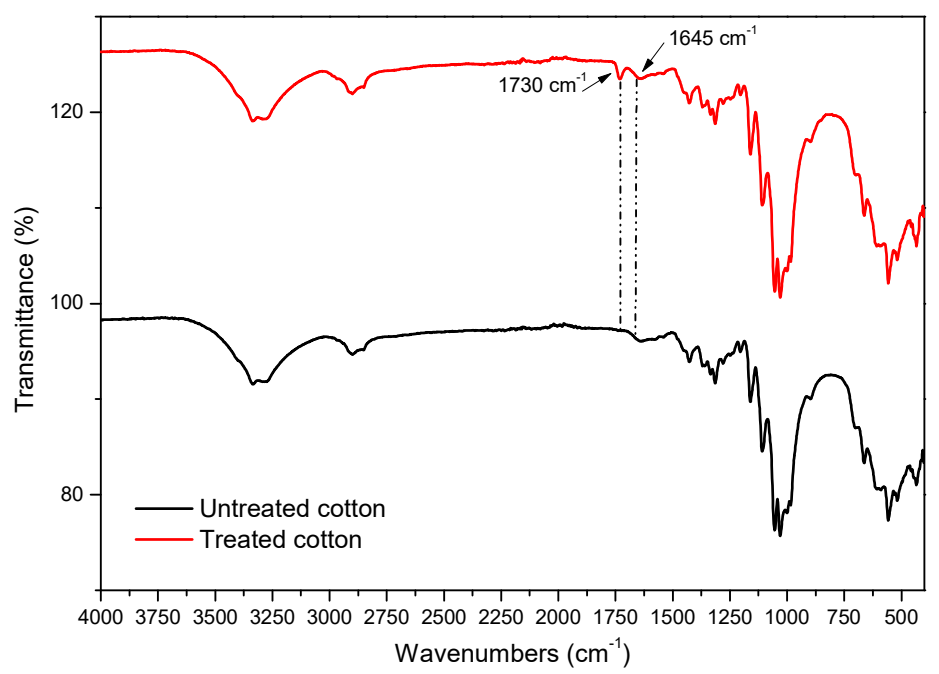

Figure 3. FTIR spectra of untreated cotton fabric and cotton fabric treated with microcapsules.

The FTIR spectra show prominent peaks of cellulose. The stretching vibration of the hydroxyl group gives a wide peak at $3300 \mathrm{~cm}^{-1}$. The band at $2890 \mathrm{~cm}^{-1}$ is characteristic of $\mathrm{CH}$ stretching vibration. Typical bands observed in the region of $1650-898 \mathrm{~cm}^{-1}$ are assigned to cellulose. The characteristic peaks of $-\mathrm{CH}_{2}$ and $-\mathrm{CH},-\mathrm{OH}$ and $\mathrm{C}-\mathrm{O}$ bonds in cellulose gives the bands at 1428, 1368, 1317, 1061 and $895 \mathrm{~cm}^{-1}$ [20].

The appearance of a new peak at $1730 \mathrm{~cm}^{-1}$ was revealed on the spectrum of the treated cotton fabric. This peak is not present in the untreated sample spectrum and it corresponds to $\mathrm{C}=\mathrm{O}$ ester stretching, which evidences the successful interaction between the chitosan (the wall of microcapsules) and cellulosic fibers through ester bond formation.

In addition, the small intensity of the peak at $1645 \mathrm{~cm}^{-1}$ is attributed to the $\mathrm{NH}$ group bending vibration, resulting from the chemical reaction between the $\mathrm{NH}_{2}$ groups of chitosan in the microcapsule walls and the $\mathrm{COOH}$ groups of the acid.

The ATR-FTIR results are in agreement with optical microscopy and SEM photographs of treated samples where the attached microcapsules were clearly seen (Figure 1).

\subsection{Mechanical Properties}

Maximum breaking load and extension were the characteristic parameters considered to evaluate mechanical properties. The two parameters were extracted from the load versus extension curves. As shown in Table 1, the maximum breaking load of untreated fabric is lower than that of the treated one. This result is due to the fact that the grafting process was conducted under acidic conditions $(\mathrm{pH}=5)$. Highly acidic mediums are known to reduce the mechanical properties of cellulose by affecting its crystalline structure. The reduction rates depend on the $\mathrm{pH}$ value. High acidic $\mathrm{pH}$ values result in an important reduction in mechanical properties.

The extension indicates the percentage of strain at maximum applied force. High extension values evidence a stretch behavior of the textile substrate. Microcapsule grafting slightly reduced the stretch rate of the fabric. However, this reduction is not considered sufficient to affect the textile properties. 
Table 1. Mechanical properties.

\begin{tabular}{ccc}
\hline Mechanical Property & Untreated Cotton & Treated Cotton \\
\hline Maximum breaking load $(\mathrm{N})$ & $430 \pm 26$ & $374 \pm 18$ \\
\hline Extension $(\%)$ & $23 \pm 0.6$ & $22 \pm 0.5$ \\
\hline
\end{tabular}

\pm Standard deviation.

\subsection{Surface Wettability}

Dynamic contact angle was used to evaluate the wetting properties of the treated fabrics. Due to the high hydrophilicity of textiles, it is difficult to evaluate their static contact angles. The time required by the fabric to totally absorb the water droplet was considered. The longer the required time, the lower the sample wettability. Figure 4 shows the wetting times. It is clear that the treated fabric presents a more hydrophilic surface compared to the control fabric. A short wetting time was recorded when the water droplet fully spread on the surface. This result can be explained by the fact that the chitosan (microcapsule wall)-treated fabric presents an important percent in oxygen and more $\mathrm{C}=\mathrm{O}$ or $\mathrm{C}-\mathrm{O}$ bonds, which are associated with the hydrophilic property.

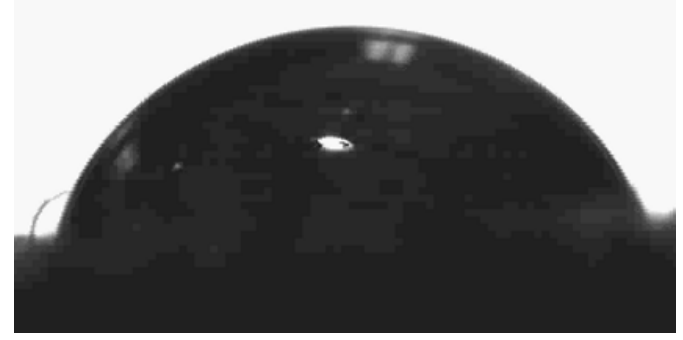

(a)

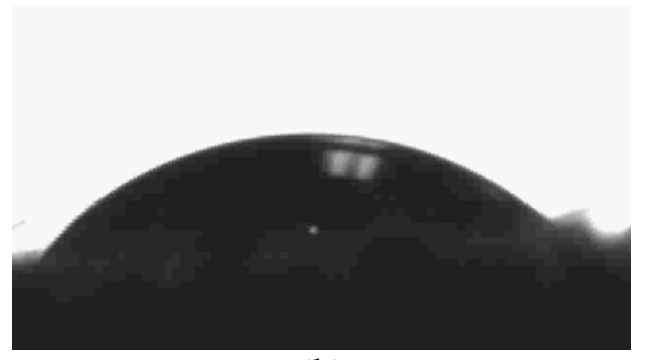

(b)

Figure 4. Water droplets on the surface of (a) untreated fabric, and (b) treated fabric after $3 \mathrm{~s}$ of contact.

\subsection{Antibacterial Activity Evaluation}

As shown in Figure 5, the extracted oils showed a remarkable antimicrobial activity. They were effective against both E.coli and S.aureus strains. A clear zone of inhibition was detected. Average distance of peripheral inhibition zone (clear zone around the disc) was measured (Table 2). An additive effect was observed when testing the activity of the oil mixture. The combined effect was greater than individual effects.

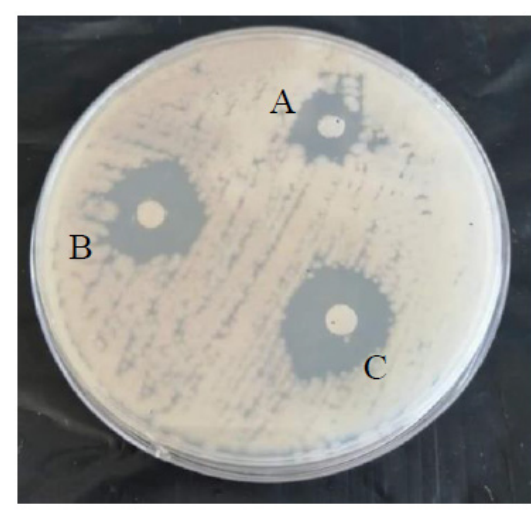

(a)

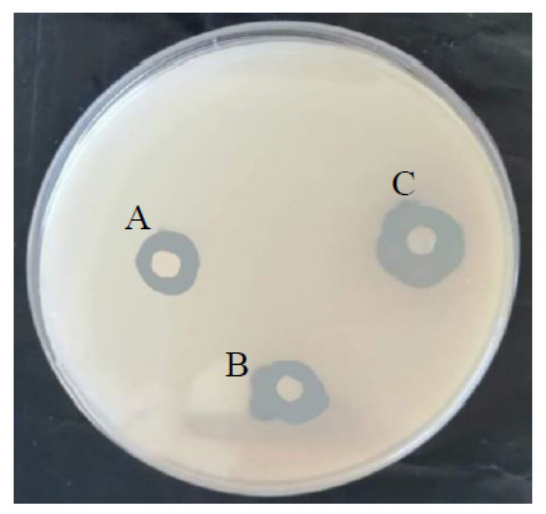

(b)

Figure 5. Antibacterial activity of essential oils in solution using agar diffusion method. A: cloves oil, B: cinnamon oil and C: oil mixture ((a): S.aureus/(b): E.coli). 
Table 2. Peripheral inhibition zones values ( $\mathrm{mm})$.

\begin{tabular}{cccc}
\hline Bacteria Strain & Cinnamon Oil & Clove Oil & Oil Mixture \\
\hline E.coli & $2.5 \pm 53$ & $1.75 \pm 0.46$ & $3.25 \pm 0.46$ \\
\hline S.aureus & $3 \pm 0.75$ & $1.75 \pm 0.46$ & $3.5 \pm 0.53$ \\
\hline
\end{tabular}

\pm Standard deviation.

Figure 6 shows that untreated samples did not present any activity since they did not show an inhibition zone around the sample.

Antibacterial activity was detected for individual oil and the mixture. A slight difference was seen between samples against the same bacteria strain and the same sample against the two bacteria strains.

The antibacterial effect exhibited by the microcapsules is predominantly due to the encapsulated essential oils during their release through the microcapsule wall and not from the chitosan itself. It is well known that chitosan is an antibacterial agent [23,24]. However, during the grafting of microcapsules onto cotton fibers, most of the positive amino groups of chitosan were complexed with negative carboxylic groups of the crosslinking agent.

Cinnamon and clove oils affect the envelope structure of Gram-positive and Gramnegative bacteria. The major antibacterial agents of these oils penetrate through the bacteria cell wall and damage the cytoplasmic membrane $[25,26]$.

a)
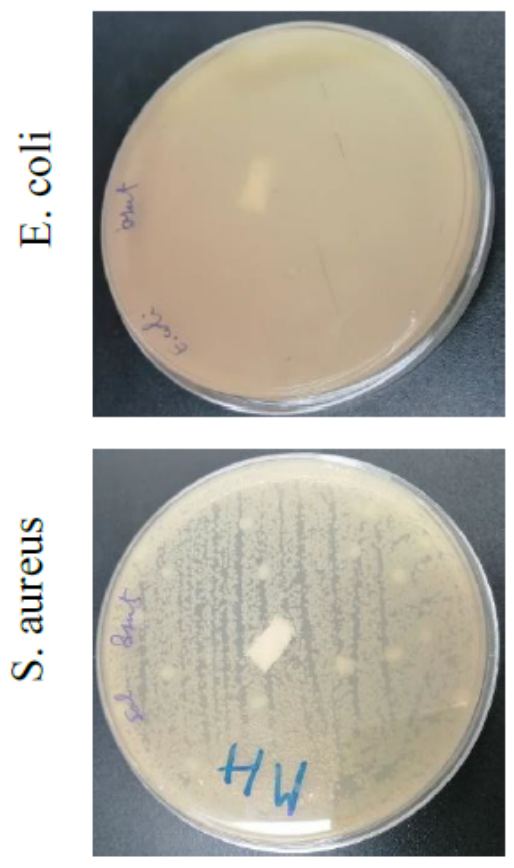

b)
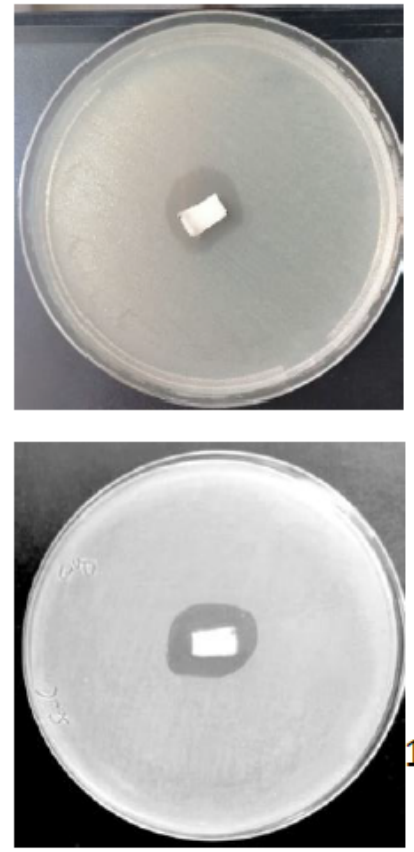

c)
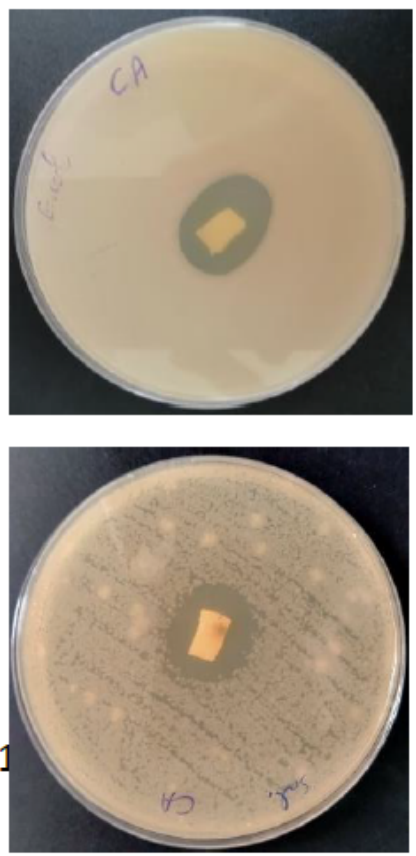

d)
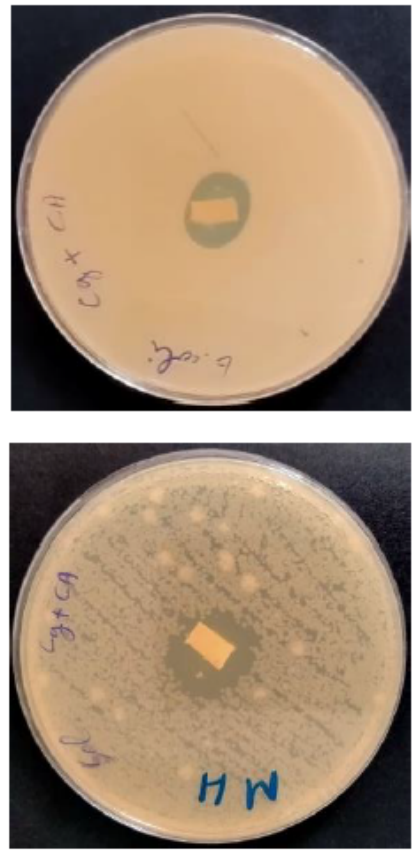

Figure 6. Antibacterial activity results of the (a) untreated cotton, (b) cotton grafted with clove oil microcapsules, (c) cotton grafted with cinnamon oil microcapsules and (d) cotton grafted with oil mixture microcapsules.

Comparing results of the inhibition obtained from the clear zones, indifference was observed when using the oil mixture. There was no interaction between one another. The combined effect was the same as when the two oils were individually applied.

Cinnamon oil exhibits good antibacterial activity. However, it is known to be an irritant oil. Combination of cinnamon oil with clove oil can avoid irritant and contact allergy reactions by using lower concentrations of the irritant oil while conserving its important activity against bacteria. 


\section{Conclusions}

Essential oils are a family of natural compounds that are well known for their biological activities. They are applied to many treatments. The goal of this work was to apply a mixture of essential oils (cinnamon oil and clove oil) for the functionalization of cellulosic fibers. Essential oils were extracted by hydro-distillation. The extracted oils were characterized by GC/MS. This technique revealed the chemical composition of each oil. Chitosan was used to produce essential oil microcapsules, which were then grafted on the cotton fabric surface via citric acid. Some textile properties were evaluated, such as wettability and mechanical properties

Finally, antibacterial activity of different samples was assessed. It was concluded that essential oil combination is a promising tool to provide antimicrobial agents with a broad spectrum of activity. Moreover, the encapsulation avoids the rapid evaporation and degradation of their active components. The application of encapsulated oil mixture enhances the efficacy against multi-resistant pathogens.

Author Contributions: Conceptualization, D.D., A.B. (Aicha Bouaziz) and S.G.; methodology, D.D., A.B. (Aicha Bouaziz) and S.G.; experiments, A.B. (Aicha Bouaziz), D.D., S.G., F.B. and A.Z.; validation, H.M., C.B. and A.B. (Aghleb Bartegi); analysis, A.B. (Aicha Bouaziz), D.D., S.G., F.B., A.Z. and H.M.; investigation, D.D., A.B. (Aicha Bouaziz) and S.G.; resources, C.B. and H.M.; writing-original draft preparation, D.D., A.B. (Aicha Bouaziz), S.G. and H.M.; writing-review and editing, D.D., A.B. (Aicha Bouaziz), S.G. and H.M.; supervision, A.B. (Aghleb Bartegi), H.M. and C.B.; project administration, S.G. and C.B. All authors have read and agreed to the published version of the manuscript.

Funding: This research received no external funding.

Institutional Review Board Statement: Not applicable.

Informed Consent Statement: Not applicable.

Data Availability Statement: Data sharing is not applicable to this article.

Conflicts of Interest: The authors declare no conflict of interest.

\section{References}

1. Pacios, O.; Blasco, L.; Bleriot, I.; Fernandez-Garcia, L.; González Bardanca, M.; Ambroa, A.; López, M.; Bou, G.; Tomás, M. Strategies to combat multidrug-resistant and persistent infectious diseases. Antibiotics 2020, 9, 65. [CrossRef] [PubMed]

2. Srivastava, J.; Chandra, H.; Nautiyal, A.R.; Kalra, S.J. Antimicrobial resistance (AMR) and plant-derived antimicrobials (PDA ms) as an alternative drug line to control infections. 3 Biotech 2014, 4, 451-460. [CrossRef] [PubMed]

3. Chen, C.K.; Lee, M.C.; Lin, Z.I.; Lee, C.A.; Tung, Y.C.; Lou, C.W.; Law, W.C.; Chen, N.T.; Lin, K.Y.A.; Lin, J.H. Intensifying the antimicrobial activity of poly [2-(tert-butylamino) ethyl methacrylate]/polylactide composites by tailoring their chemical and physical structures. Mol. Pharm. 2018, 16, 709-723. [CrossRef] [PubMed]

4. Hoque, J.; Prakash, R.G.; Paramanandham, K.; Shome, B.R.; Haldar, J. Biocompatible injectable hydrogel with potent wound healing and antibacterial properties. Mol. Pharm. 2017, 14, 1218-1230. [CrossRef]

5. Subramani, R.; Narayanasamy, M.; Feussner, K.D. Plant-derived antimicrobials to fight against multi-drug-resistant human pathogens. 3 Biotech 2017, 7, 1-15. [CrossRef]

6. Ladan, Z.; Amupitan, J.; Oyewale, O.; Ayo, R.; Temple, E.; Ladan, E. Phytochemical screening of the leaf extracts of Hyptis spicigera plant. Afr. J. Pure Appl. Chem. 2014, 8, 83-88.

7. Santamaria, M.E.; Martínez, M.; Cambra, I.; Grbic, V.; Diaz, I. Understanding plant defence responses against herbivore attacks: An essential first step towards the development of sustainable resistance against pests. Transgenic Res. 2013, 22, 697-708. [CrossRef]

8. Trifan, A.; Luca, S.V.; Greige-Gerges, H.; Miron, A.; Gille, E.; Aprotosoaie, A.C. Recent advances in tackling microbial multidrug resistance with essential oils: Combinatorial and nano-based strategies. Crit. Rev. Microbiol. 2020, 46, 338-357. [CrossRef]

9. Akthar, M.S.; Degaga, B.; Azam, T. Antimicrobial activity of essential oils extracted from medicinal plants against the pathogenic microorganisms: A review. J. Issues ISSN 2014, 2350, 1588.

10. Xianfei, X.; Xiaoqiang, C.; Shunying, Z.; Guolin, Z. Chemical composition and antimicrobial activity of essential oils of Chaenomeles speciosa from China. Food Chem. 2007, 100, 1312-1315. [CrossRef]

11. Walentowska, J.; Foksowicz-Flaczyk, J. Thyme essential oil for antimicrobial protection of natural textiles. Int. Biodeterior. Biodegrad. 2013, 84, 407-411. [CrossRef]

12. Jugreet, B.S.; Suroowan, S.; Rengasamy, R.; Mahomoodally, M.F. Chemistry, bioactivities, mode of action and industrial applications of essential oils. Trends Food Sci. Technol. 2020, 101, 89-105. [CrossRef] 
13. Ghayempour, S.; Montazer, M. Micro/nanoencapsulation of essential oils and fragrances: Focus on perfumed, antimicrobial, mosquito-repellent and medical textiles. J. Microencapsul. 2016, 33, 497-510. [CrossRef] [PubMed]

14. Lammari, N.; Louaer, O.; Meniai, A.H.; Elaissari, A. Encapsulation of essential oils via nanoprecipitation process: Overview, progress, challenges and prospects. Pharmaceutics 2020, 12, 431. [CrossRef]

15. Sayed, U.; Sharma, K.; Parte, S. Application of essential oils for finishing of textile substrates. J. Text. Eng. Fash. Technol. 2017, 1, 42-47. [CrossRef]

16. Tawiah, B.; Badoe, W.; Fu, S. Advances in the development of antimicrobial agents for textiles: The quest for natural products. Review. Fibres Text. East. Eur. 2016, 3, 136-149. [CrossRef]

17. Singh, R. Antimicrobial activity of selected medicinal plants cinnamon and clove. Int. J. Res. Pharm. Pharm. Sci. 2018, 3, 48-50.

18. Adesiji, Y.; Alli, O.; Shittu, A.; Oluremi, A. Antibacterial activity of cinnamon and clove oil on different food borne bacterial isolates. Nig. J. Pure Appl. Sci. 2015, 28, 2610-2616.

19. Sharkawy, A.; Fernandes, I.P.; Barreiro, M.F.; Rodrigues, A.E.; Shoeib, T. Aroma-loaded microcapsules with antibacterial activity for eco-friendly textile application: Synthesis, characterization, release, and green grafting. Ind. Eng. Chem. Res. 2017, 56, 5516-5526. [CrossRef]

20. Bouaziz, A.; Dridi, D.; Gargoubi, S.; Zouari, A.; Majdoub, H.; Boudokhane, C.; Bartegi, A. Study on the Grafting of ChitosanEssential Oil Microcapsules onto Cellulosic Fibers to Obtain Bio Functional Material. Coatings 2021, 11, 637. [CrossRef]

21. Yuan, L.; Sun, T.; Hu, H.; Yuan, S.; Yang, Y.; Wang, R.; Lyu, C.; Yang, F.; Lyu, X. Preparation and characterization of microencapsulated ethylenediamine with epoxy resin for self-healing composites. Sci. Rep. 2019, 9, 1-10.

22. Javid, A.; Raza, Z.A.; Hussain, T.; Rehman, A. Chitosan microencapsulation of various essential oils to enhance the functional properties of cotton fabric. J. Microencapsul. 2014, 31, 461-468. [CrossRef]

23. Hoque, J.; Adhikary, U.; Yadav, V.; Samaddar, S.; Konai, M.M.; Prakash, R.G.; Paramanandham, K.; Shome, B.R.; Sanyal, K.; Haldar, J. Chitosan derivatives active against multidrug-resistant bacteria and pathogenic fungi: In vivo evaluation as topical antimicrobials. Mol. Pharm. 2016, 13, 3578-3589. [CrossRef] [PubMed]

24. Chen, C.-K.; Liao, M.-G.; Wu, Y.-L.; Fang, Z.-Y.; Chen, J.-A. Preparation of highly swelling/antibacterial cross-linked N-maleoylfunctional chitosan/polyethylene oxide nanofiber meshes for controlled antibiotic release. Mol. Pharm. 2020, 17, 3461-3476. [CrossRef] [PubMed]

25. Zhang, Y.; Liu, X.; Wang, Y.; Jiang, P.; Quek, S. Antibacterial activity and mechanism of cinnamon essential oil against Escherichia coli and Staphylococcus aureus. Food Control 2016, 59, 282-289. [CrossRef]

26. Weerakkody, N.S.; Caffin, N.; Turner, M.S.; Dykes, G.A. In vitro antimicrobial activity of less-utilized spice and herb extracts against selected food-borne bacteria. Food Control 2010, 21, 1408-1414. [CrossRef] 